\title{
Mechanisms of Competitive Displacement of Native Ant Fauna by Invading Myrmica rubra (Hymenoptera: Formicidae) Populations
}

\author{
JEFFREY GARNAS, ${ }^{1,2,3}$ ELEANOR GRODEN, ${ }^{4}$ AND FRANCIS A. DRUMMOND ${ }^{4}$
}

\begin{abstract}
Environ. Entomol. 43(6): 1496-1506 (2014); DOI: http://dx.doi.org/10.1603/EN14079
ABSTRACT Exotic ants have become invasive in many regions around the world, with variable ecological impacts. Postinvasion, native ant communities are often found to be depauperate, though the causes of this apparent lack of coexistence are rarely well known. Myrmica rubra (L.), a Palearctic Myrmecine ant, is currently expanding its range as an invasive in North America. This aggressive ant forms dense, patchy local infestations and appears to aggressively displace native ant fauna. We measured behavioral interactions and rates of recruitment in experimental field assays pitting native foragers against captive colonies of M. rubra at tuna-jelly or aphid baits in uninfested areas of Mt. Desert Island, ME. Behavioral interactions were idiosyncratic with respect to the native opponent, but M. rubra generally showed significantly higher levels of recruitment, aggression, and displacement of native foragers. As with other invasive ant species shown to have broken the "dominance-discovery trade-off," M. rubra was consistently faster to discover baits and disproportionately displaced native foragers, providing a plausible proximate mechanism for native ant exclusion. Finally, we surveyed ant recruitment at baits for $24 \mathrm{~h}$ in August 2004 at four sites with varying M. rubra abundance but found little evidence of temporal niche partitioning. Taken together, these results indicate competitive superiority by M. rubra with respect to native ant communities of the northeastern North America and suggest direct aggression and competitive exclusion at food resources can lead to local native displacement.
\end{abstract}

KEY WORDS dominance-discovery trade-off, invasive ant, coexistence, European fire ant, ruby ant

Exotic ant species have had a detrimental impact on native ant fauna in all but the most marginal habitats within newly invaded ranges, at least in the early stages of invasion (Porter and Savignano 1990, Morrison 2002, Rowles and O'Dowd 2009). While a few "tramp ants" may be so closely associated with human activity and disturbance as to specialize largely on open niche habitat (Passera and Williams 1994), the superior competitive ability of many invasive species is demonstrated by their widespread ecological success and numerical dominance in habitats once occupied by rich and varied native ant communities $(\mathrm{Hu}-$ man and Gordon 1996, Holway 1998, Holway and Case 2001, Holway et al. 2002, Carpintero and Reyes-Lopez 2008). Although some evidence that such negative effects (i.e., virtual extirpation of native ant fauna) may be transient (Sanders et al. 2001, Morrison 2002) and context-dependent (Menke and Holway 2006, Heller et al. 2008), lasting changes in community structure appear to be the norm (Sanders et al. 2003, Holway and Suarez 2006, Lessard et al. 2009b).

\footnotetext{
${ }^{1}$ Present address: Department of Zoology and Entomology, University of Pretoria, Pretoria, South Africa 0002.

${ }^{2}$ Forestry and Agricultural Biotechnology Institute (FABI), University of Pretoria, Pretoria, South Africa 0002.

${ }^{3}$ Corresponding author, e-mail: jeff.garnas@fabi.up.ac.za.

${ }^{4}$ College of Natural Sciences, Forestry, and Agriculture, School of Biology and Ecology, University of Maine, Orono, ME 04469.
}

Ultimate explanations for the apparent dominance of invasive ants include the release from natural enemies (Porter et al. 1997, Tsutsui et al. 2003, Yang et al. 2010), the breakdown of nestmate recognition leading to low intraspecific aggression and high colony density (Tsutsui et al. 2000, Starks 2003), or "preselection" for aggression and dominance among invasive forms (Davidson 1998; Holway 1998, 1999; Giraud et al. 2002). Invading foragers may also have an energetic advantage at high densities given an apparent surplus of carbohydrates from homopteran sources relative to the availability of protein (Davidson 1998, Helms and Vinson 2008, Wilder et al. 2011, Shik and Silverman 2012). Despite the importance of invasive ant species on biodiversity and ecosystem function on a global scale, the mechanisms driving displacement of native fauna have only been studied in a handful of species (Kenis et al. 2009). Understanding these mechanisms could help predict the trajectory of community change, asymmetric impacts across taxa, and associated changes in biodiversity in the wake of an invasion.

Among the best-studied exotic ants from the perspective of competitive displacement of native fauna is the Argentine ant (Linepithema humile (Mayr, 1868) ). These ants are disproportionately successful at exploiting bait resources by maintaining higher colony activity levels, foraging for longer periods each day and recruiting in greater numbers to food resources 
when compared with their native counterparts $(\mathrm{Hu}-$ man and Gordon 1996). The more numerous L. humile workers have also proved to be better interference competitors, displacing native species from contested baits in the majority of trials, often via direct combat or aggression. This represents an apparent break in the "dominance-discovery trade-off" (or interference-exploitation; Fellers 1987), which is cited as a mechanism promoting diversity and coexistence in native ant communities by "leveling the playing field," with respect to resource acquisition. This break has been suggested as a proximate mechanism for invasive ant success and the reduction in native richness that often follows (Davidson 1998, Adler et al. 2007, PearceDuvet et al. 2011).

In addition to life history trade-offs in foraging strategy, other possible mechanisms for coexistence in diverse ant communities have been recognized. These include niche differentiation via nonoverlapping microhabitat requirements (Lessard et al. 2009a), diets (Ryti and Case 1984, Palmer 2004, Achury et al. 2008) or foraging activity (Kronfeld-Schor 2003), contextdependence in competitive outcomes, environmental stochasticity (Andersen 2008), and spatial heterogeneity and complexity (Gause 1932, Tokeshi 1999, Palmer 2003). The importance and generality of such mechanisms in maintaining community diversity and the degree to which the disruption of key trade-offs explains competitive displacement by invasive ants are largely unknown.

Myrmica rubra (L.), a Palearctic Myrmicine with a native range stretching west to east from Spain and the British Isles to Central Asia and south to north from the Mediterranean coast through Scandinavia and central Russia, was introduced to North America around the turn of the 20th Century, sometime before 1908 (Wheeler 1908, Elmes 1974, Collingwood 1979). The species established in Maine sometime in the 1930s and is now present in a minimum of 42 Maine localities (Groden et al. 2005). Colonies are diffuse, often spread across multiple satellite nests, each containing up to 5,000 or more workers and between 15 and 30 queens (Groden et al. 2005, Garnas et al. 2007). Colony structure is similar in Europe, though colony density is greatly reduced (Radchenko and Elmes 2010). M. rubra is patchily distributed across its known range in Maine, parts of northeastern North America, Washington State, and British Columbia (Wetterer and Radchenko 2011), forming locally dense infestations in all invaded regions studied to date. Within such infestations, most native ants are conspicuously absent or at low densities, though occasional foragers of another species may sometimes be found (Garnas et al. 2007, McPhee et al. 2012).

As a generalist predator, scavenger, and homopteran associate, M. rubra shows considerable overlap in food resources with most sympatric native ant species (Groden et al. 2005, McPhee et al. 2012). Given the high density of workers and its apparent competitive superiority, we hypothesized that like the Argentine ant, M. rubra is both the first to discover and exploit a food resource and to maintain dominance over that resource, to the exclusion of native foragers. This would represent a break in the "dominancediscovery trade-off" and is a potential mechanism contributing to native ant displacement along the M. rubra advancing invasion front. We used a combination of field assays using mobile nests and natural recruitment at baits to examine patterns of interspecific aggression in areas currently dominated by a rich variety of native ants in coastal Maine. In areas very recently colonized by $M$. rubra where native ants persist, we used baiting trials to assess the hypothesis that rates of discovery of food resources and direct aggression and the ability to displace native ants do not trade-off in this invader but rather explain elements of the competitive success of this species. Finally, we report on the potential for temporal niche partitioning using overnight trapping surveys.

\section{Materials and Methods}

Mobile Nest Establishment. Ten M. rubra colony fragments were excavated from five spatially disjunct populations on Mt. Desert Island, ME, and transferred to Rubbermaid tubs (9.8 liters). Each nest contained between 1,380 and 5,170 workers (mean \pm SD = $3,020 \pm 1,306), 850$ and 3,500 larvae $(1,613 \pm 879)$, and 10 and 37 queens $(18.7 \pm 9.5)$. Captive nest size was shown to have little effect on overall aggressive behavior or recruitment. A 15- by $15-\mathrm{cm}$ foraging arena was attached to each nest box via $20 \mathrm{~cm}$ of Tygon tubing, where ants were provided with a daily supply of field-collected insects, $20 \%$ sucrose solution, and water-soaked gauze. Sides of the foraging arena were coated with Fluon to prevent climbing. Details of establishment and care are given in Garnas et al. (2007). These nests were used for all aggression assays with native ants. Nests were labeled with a unique code to allow for blind assays irrespective of colony origin or nest size, and the order of colony usage in assays was randomized within weeks from the beginning of the season. Randomization was stratified so that no captive nest was used more than twice per week during the 12 wk of the experiment.

Assay Protocols. We measured behavioral interactions, rates of recruitment, and displacement at baits between 1) naturally recruiting native ant and $M$. rubra foragers along the edge of two known M. rubra infestations, and 2) naturally recruiting native foragers and M. rubra workers from captive mobile colonies recruiting to arenas containing either a) tuna-jelly baits or b) honeydew-producing aphids.

Natural Recruitment Assays. M. rubra so thoroughly excludes native ants from all but the most marginal habitats that experiments can only successfully take place along the advancing front of an infestation where densities of $M$. rubra are comparatively low. We performed five replicates using natural recruitment (against Myrmica fracticornis (Forel) $[n=$ 2], Formica glacialis (Wheeler) $[n=2]$, and Temnothorax ambiguus (Emery) $[n=1]$ ). Suitable natural recruitment by both native ants and M. rubra such that interactions at baits could be quantified was rare but 
offered a valuable control for the effect of using captive colonies in our assays.

Baited Arena Assays. One wall of the foraging arena was cut away and opened to allow recruitment by native ants; the other was attached via Tygon tubing, fitted with a rubber stopper to a nest box containing a single captive M. rubra nest. This allowed for the placement of captive nests in noninfested sites where native ants could recruit to baits while M. rubra was still contained. Fresh foraging arenas that had been thoroughly washed in soapy water, sprayed with $70 \%$ ethanol and dried with a paper towel were used for all assays to avoid any possible influence of persistent odors or pheromone trails. The sides of each arena were freshly painted with Fluon so that entrance or exit was possible only through the captive nest tube or the opposite wall which had been cut away. Captive nests and arenas were left in proximity to a known native ant foraging territory for up to $14 \mathrm{~h}$, until a minimum of 10 native foragers were present simultaneously at the baits, wherever possible. Recruitment was consistently low for Camponotus and Temnothorax species; in such cases assays were performed when recruitment had reached a minimum of five workers. Once a sufficient number of native foragers were present, rubber stoppers were removed, allowing M. rubra access to the bait and arena and marking the start of the behavioral assay. Aggressive and nonaggressive interactions were tallied in 2-min observation intervals beginning when the first $M$. rubra worker entered the arena and continuing for as long as it took one species to fully displace the other from the bait (with a minimum recording time of 10 $\min$ ).

Assay Protocols-Aphid Assays. The second aggression assay employed a similar design, but native foragers naturally tending live aphid colonies were used as opponents for M. rubra instead of attracting native foragers to the arenas using tuna-jelly baits. Most of the assays were conducted on small Populus tremuloides (Michx.) saplings $(\approx 40 \mathrm{~cm}$ in height), though assays against Crematogaster cerasi (Fitch) and Formica lasioides (Emery) were conducted on isolated stems of Spiraea alba (Duroi) growing wild. In no instance did the root collar diameter exceed $1 \mathrm{~cm}$. A small hole (just larger than the base of the sapling) was cut in the bottom of the foraging arena, along with a slit that allowed it to be slipped at the base of the tree or branch. The slit was then closed with clear packing tape so as to minimize the number of ants falling from the arena while permitting movement in and out. Effects of forager disruption during arena setup were minimized by allowing a 15-min rest period before beginning the assays. As with the arena assays, behavioral interactions were tallied in 2-min periods for between 10 and $60 \mathrm{~min}$. Assays were terminated when active recruitment by both colonies ceased.

Behavioral Tallies. With an observer and a recorder present, it was possible to tally all of the behavioral interactions that took place throughout the duration of the assay. Behaviors were assigned to one of the following categories: antennation, attack, grasp- ing, carrying, fighting, escape, or trophallaxis (Garnas et al. 2007). Antennation occurred when one ant tapped or passed its antenna over the cuticle of another. Attacks were tallied when one ant lunged toward another with mandibles open and preceded all other aggressive interactions such as fights or grasping. Grasping was tallied when an ant held a part of another ant in its mandibles, either briefly or for an extended period, and was often characterized by a combined attack by five or more ants pulling the opposing forager in opposing directions. Carrying behavior occurred when one ant lifted another off the floor of the arena for a period of more than two seconds. Because both grasping and carrying behavior occurred for variable lengths of time, each was tallied once for each 2 -min interval in which it occurred. With the exception of fight behavior where both ants locked in battle attempting to sting or spray each other, behaviors were assigned to one or the other species as appropriate. Fights were assigned to both captive and native foragers, as it was impossible to determine the originator of aggression in this case. Escape behavior was tallied when one ant came in close contact with another and rapidly moved off. Trophallaxis, or social feeding, was not observed in any of the interspecific aggression trials.

The number of foragers of each species present in the arena and the number of ants actively feeding at the baits were counted at the beginning of each assay and then at the end of each 2-min interval. At the end of each assay, M. rubra foragers were collected from the arena and from the habitat and were returned to the nest box. A representative sample of the native ant was collected for species identification.

Aggression Scores. To assess total aggression for each assay and make comparisons both within and among species, an overall aggression score was calculated for M. rubra and the native species for each trial. Scores were calculated by the following weighted formula, after de Vroey (1980):

Aggression score $=[\mathrm{A}+2 \mathrm{G}+2 \mathrm{C}+3 \mathrm{~F}] /$

[Duration of assay $(\min )] \times 10$

where A, G, C, and F are the total count of attacks, grasps, carries, and fights, respectively, tallied through the course of the assay.

Because assay duration varied among trials, we standardized scores to a 10-min assay for ease of comparison.

Discovery Time Experiment. To measure the relative time to discovery and recruitment to food resources by $M$. rubra and native ant foragers in the absence of experimental manipulations, baits were monitored for the arrival of ants for a period of $2 \mathrm{~h}$ at a single site in Acadia National Park. Beginning at 7 a.m. on 20 August 2004, 40 petri dish lids baited with a $1 \mathrm{~cm}^{2}$ of gauze soaked in $25 \%$ sucrose solution were placed along two transects in an M. rubra infested site within Acadia National Park $\left(44.36^{\circ} \mathrm{N}, 68.20^{\circ} \mathrm{W}\right)$. Transect direction was randomized under the constraint that it span the preidentified edge of a local 
infestation. Sugar was used as bait for convenience and proved effective in attracting a broad cross-section of sympatric native ant species (Hölldobler and Wilson 1990), and no major differences in species composition among foragers recruiting to protein versus carbohydrate baits were observed during the course of this study. A cap from a 25-cubic centimeter (cc) scintillation vial was filled with sugar solution and inverted on each piece of gauze to ensure that the baits would not dry out. Baits were monitored every $15 \mathrm{~min}$ for the next $2 \mathrm{~h}$, and the presence and number of each ant genus (species identifications were made in the field where possible) was recorded. Care was taken not to disturb feeding or foraging by maintaining at least $1 \mathrm{~m}$ observation distance. At the end of the experiment, dishes were capped and transferred to the laboratory for species verification.

Temporal Foraging Survey. To assess potential temporal partitioning in foraging activity across ant species, 24-h sampling using sugar-baited vials was performed in Acadia National Park in August 2004. Four sites were selected, including one site where $M$. rubra was absent (Sand Beach House North), two sites where M. rubra was present at low density and limited to a small section of the sampling area (Great Meadow and Sieur du Mont Springs), and a fourth site representing a dense M. rubra infestation (Sand Beach House South). Twenty 25-cc scintillation vials were baited with sugar-soaked gauze and placed randomly throughout each of the four sites, beginning at 4 p.m. on 19 August 2004. Every $3 \mathrm{~h}$ for $24 \mathrm{~h}$, foragers that had recruited to the interior of the vial were counted and released. To identify native ants to species, up to eight workers per vial and time point were preserved in $80 \%$ ethanol. Each trap was replaced with clean, freshly baited vials placed on the vegetation or soil surface 1-2 $m$ away to avoid recapture of the same ants or bias due to prerecruitment.

Ant Identification. Representative samples of all ants encountered in this study were collected in the field and preliminarily identified to genus (or to species where possible) by the authors. A subset of these ants was sent to Dr. André Francouer, Chicoutimi, Quebec, Canada for correct determination to species, and another was confirmed at the Harvard Museum of Comparative Zoology with the assistance of Mr. Stefan Cover. Many of the species in this study were previously cited in Ouellette et al. (2010). Voucher specimens are stored at the University of Maine, Orono.

Data Treatment and Analysis. Data from the aggression assays were analyzed as total aggression scores, individual aggression counts by behavior, and counts of overall aggressive behaviors as dependent variables in independent one-way ANOVA models, with the native ant species or genus as the independent variable. Separate models were run for bait versus aphid assays. Model assumptions were satisfied by square root and natural log transformations of counts and aggression respectively. Site of assay, captive nest, queen and worker number, time of day or season, and a variety of temperature and weather patterns were included in early models, but no differences were evident, and these variables were subsequently dropped. Paired $t$-tests were used to look for differences between M. rubra and native ant aggression by species, and pairwise testing was performed when comparing across species using Tukey's HSD.

In the discovery time-dominance survey, time to discovery was used as the dependent variable in an ANOVA model, with species as the independent variable. Recruitment was assessed using a repeated measures ANOVA, and pairwise differences between $M$. rubra colonization and each native genus present were assessed using Holm's correction for multiple tests (Holm 1979). Pairwise comparisons between each genus and M. rubra were performed using a one-tailed Dunnett's test. Dependent variables were natural log-transformed to fit assumptions of normality and homogeneity of variance.

All statistics were performed in SYSTAT software, version 11.00.01 (Systat Software 2012) or in R v. 2.15 (R Core Team 2012).

\section{Results}

Aggression Assays. Nearly all species tested in the baited arenas displayed considerable aggression upon encountering one another. Natural recruitment assays at baits (performed as a form of control for the use of arenas and captive nests) were qualitatively similar to captive nest assays but were characterized by low recruitment by M. rubra at the low density edge of an expanding local population. Aggression indices ranged from 4 to 49 for M. rubra and from 0 to 29 for native ants, but mean aggression exhibited by $M$. rubra and each pairwise opponent did not differ statistically (paired $t=1.0, \mathrm{df}=3, P=0.40$; excluding Temnothorax ambiguus as aggressive interactions were absent). Across assay types, aggressive behavior was dominated by attacks, followed by grasping and fighting, while carrying and escape behavior was rare. For captive colonies, mean aggression was higher for M. rubra when assayed against native ants than in our intraspecific assays for aggression score $(204.8 \pm 33.5$ vs $108.9 \pm 1.31 ; F=10.7 ; \mathrm{df}=1,37 ; P=0.002)$ and cumulative count of aggressive events $(119.8 \pm 18.4 \mathrm{vs}$ $73.2 \pm 8.8 ; F=7.0 ; \mathrm{df}=1,37 ; P=0.011)$. Aggression score varied significantly by species (MANOVA $F \approx$ $6.5 ; \mathrm{df}=10,24 ; P<0.0001 ;$ Fig. 1 ) but not by assay type (MANOVA $F \approx 0.09 ; \mathrm{df}=2,24 ; P=0.91 ;$ Fig. 1 ). Paired scores were marginally higher for $M$. rubra than for native ants when pooled across species $(t=2.0 ; \mathrm{df}=$ 26; $P=0.055)$, though this was not the case for all species (Fig. 1). There was no strong evidence of asymmetric aggression given the strong positive correlation between $M$. rubra and native scores across species $(r=0.85$; $\mathrm{df}=25 ; P<0.0001)$. Mean aggression score (averaged for M. rubra and native foragers for each assay) did not differ among species $(F=0.2$; $\mathrm{df}=4,10 ; P=0.93)$ except in the case of Temnothorax longispinosis (Roger), which did not engage in aggressive behaviors, very likely due to its small size relative to M. rubra. 


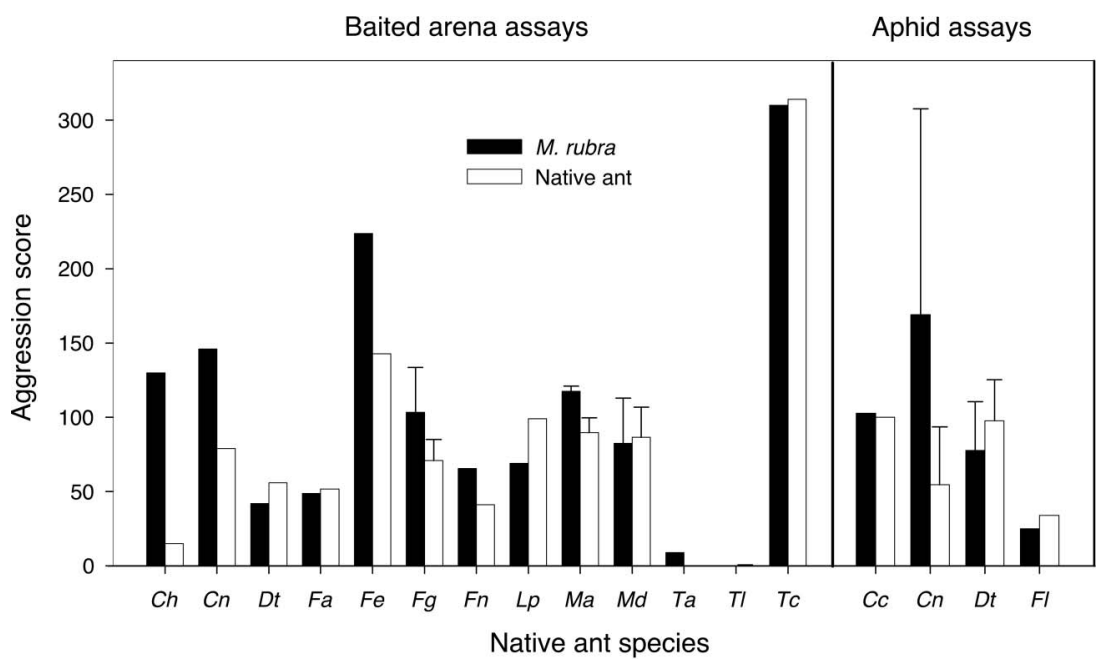

Fig. 1. Mean ( \pm SE) aggression scores for M. rubra and native ant foragers in baited arena and aphid arena assays. Baited assays: Ch, Camponotus hurculeanus (L.); Cn, C. novaboracensis (Fitch); Dt, Dolichoderus taschenbergi (Mayr); Fa, Formica aserva (Forel); Fe, F. exsectoides (Forel); Fg, F. glacialis; Fn, F. neogagates (Viereck); Lp, Lasius pallitarsus (Provancher); Ma, Myrmica americana (Weber); Md, M. detritinodis (Emery); Ta, Temnothorax ambiguus; Tl, T. longispinosis; Tc, Tetramorium caespitum (L.). Aphid assays: Cc, Crematogaster cerasi; $C n$ and Dt (as above); Fl, Formica lasioides.

Patterns of Displacement During Aggression Trials. Aggression assays between M. rubra and sympatric native ant species yielded several distinct patterns of displacement from the food resource (Fig. 2). Re- cruitment by M. rubra was typically strong in both the arena and the aphid assays (solid black lines, Fig. 2a-t and $\mathrm{u}-\mathrm{z}$, respectively). In the arena assays, a large proportion of $M$. rubra foragers were able to feed
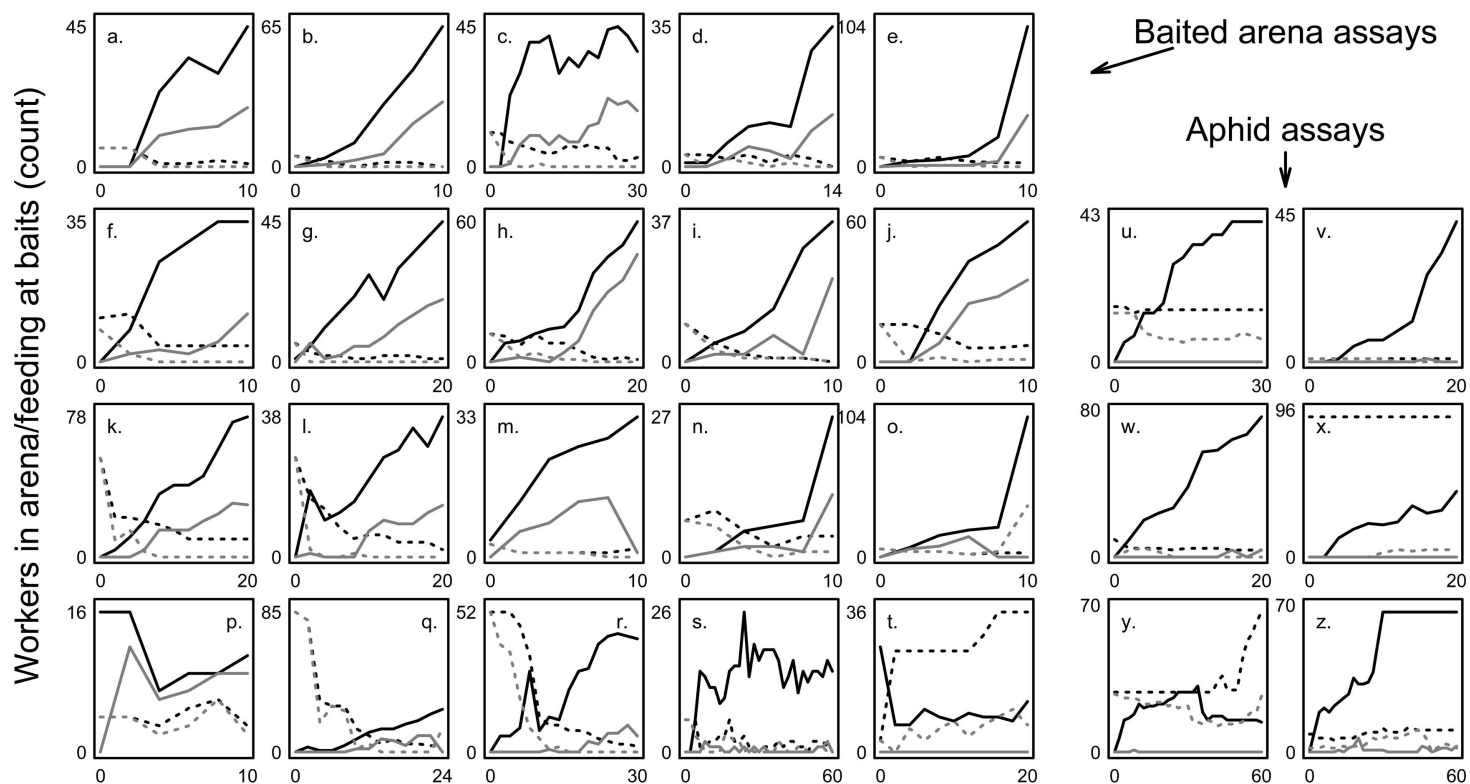

Time (minutes)

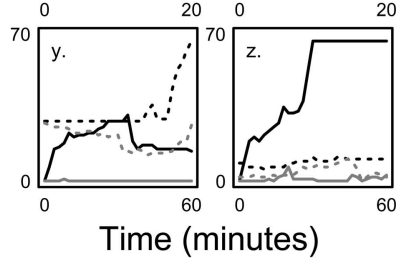

Fig. 2. Temporal patterns in worker abundance and feeding by M. rubra (solid lines) and native foragers (dotted lines) during aggression assays in sugar-protein $(\mathrm{a}-\mathrm{t})$ and aphid-baited arenas $(\mathrm{u}-\mathrm{z})$. Black lines represent the total number of workers present in the arenas while gray lines represent the number of ants actively feeding. Native opponents were as follows: (a) Camponotus hurculeanus; (b, v-w) Camponotus novaboracensis; (c) Formica exsectoides; (d-f) Formica glacialis; (g) Formica neogagates; (h-j) Myrmica detritinodis; (k) Tetramorium caespitum; (l) Lasius pallitarsis; (m-o) Temnothorax longispinosis; (p) Temnothorax ambiguus; (q-r) Myrmica americana; (s) Formica aserva; (t, x-y) Dolichoderus taschenbergi; (u) Crematogaster cerasi; (z) Formica lasioides. 


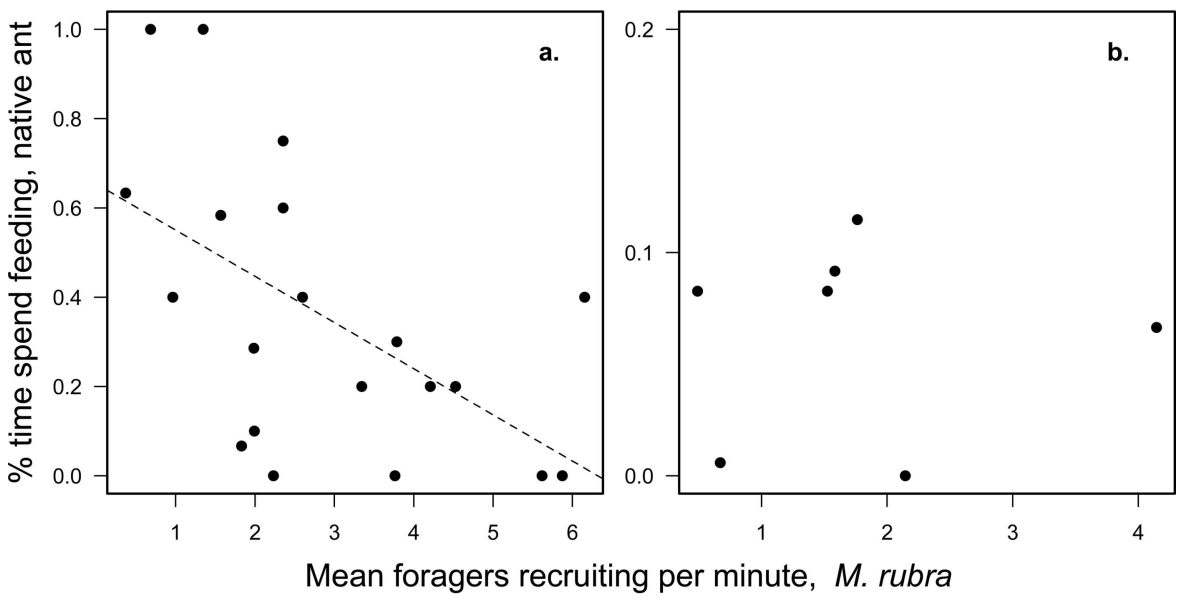

Fig. 3. Proportion of time native ant foragers spent at baits as a function of M. rubra recruitment rate in (a) baited arena assays and (b) aphid arena assays. Native ants were considered to be feeding in each 1-min interval if $>1$ forager was present and in contact with bait.

(solid gray lines), even in the midst of a high aggressive interaction with the native workers, though this was not the case in the aphid trials. By design, no $M$. rubra foragers were actively feeding at the beginning of the assays, while the majority of the native foragers in the arena were present at the bait. Workers of $M$. rubra displaced native foragers from baits in the majority of the trials (Fig. 2a-l) typically within the first 2-4 min, though in some cases (e.g., Fig. $2 \mathrm{~d}-$ e) some feeding continued. Aggression against Temnothorax species (Fig. $2 \mathrm{~m}-\mathrm{p}$ ) was extremely low with only a few attacks and no instances of grasping, carrying, or fighting; in most assays both species colonized the baits and were not observed to interact. M. rubra assays against M. americana (Fig. 2q-r) were characterized by relatively high aggression and rapid, complete displacement of the native foragers from the bait, though some native foragers returned repeatedly despite being attacked. Formica aserva is an agile and dominant ant and continued to remove bits of the bait occupied by M. rubra (Fig. 2r). Dolichoderus taschenbergi (Fig. 3t) were dominant both in terms of aggressive interactions (apparently due to toxic chemical weaponry) and in bait domination. On the structurally complex saplings during aphid assays, M. rubra was only successful at feeding briefly and sporadically in four of the six assays (Fig. $2 \mathrm{v}, \mathrm{w}, \mathrm{y}$, and $\mathrm{z}$ ), and no clear dominance over or displacement from the resource was in evidence. Direct tending or feeding by the native workers varied widely but was not demonstrably impacted by the presence of M. rubra in two of the six trials (Fig. $2 u$ and $x$ ). Overall, displacement of native ants was correlated with the rate of $M$. rubra forager recruitment in the baited arena $(\mathrm{r}=-0.55, \mathrm{df}=18, P=0.01$; Fig. 3a) but not in the aphid trials $(r=0.04, \mathrm{df}=5, P=$ 0.93 ; Fig. 3b). Interestingly, there was no evident pattern or relationship between time to displacement of the native ant and aggression score for M. rubra or native ant aggression.
Dominance and Discovery Time. M. rubra foragers were both the first to discover food and had the strongest recruitment when compared with native ants. Over the $2 \mathrm{~h}$ of this experiment, 34 of 40 baits $(85 \%)$ were colonized at one or more of the observation intervals. At least eight species including $M$. rubra were detected at baits and differed significantly in the mean time to bait discovery $(F=3.9 ; \mathrm{df}=7,27$; $P<0.0001$; Fig. 4). The number of $M$. rubra workers present at colonized baits rose sharply within the first observation interval and continued to increase steadily over the course of the experiment. Mean $M$. rubra recruitment was significantly higher than any of the native ants (repeated measures ANOVA, $F=4.5$; $\mathrm{df}=41 ; P=0.004 ;$ Holm's-corrected $P<0.05$ for all pairwise comparisons with M. rubra; Fig. 4a). Next to M. rubra, other Myrmica species were the most abundant at baits, and their numbers tended to increase steadily over time. Recruitment was generally low for Camponotus, Formica, and Lasius species, whose foragers would arrive singly or in small groups and rarely mounted any significant recruitment effort, with the exception of a few baits.

Foragers observed at baits that were not collected at the final time point were classified to genus only (Fig. 4b). Discovery time also differed by genus $(F=$ $4.2 ; \mathrm{df}=5,42 ; P=0.003$; Fig. 4b). Out of the 15 baits that $M$. rubra colonized, 13 were colonized by the first observation interval (within $15 \mathrm{~min}$ ). The mean time to discovery for $M$. rubra foragers was $21 \mathrm{~min}$, which is likely an overestimate, as many baits were colonized nearly immediately but were not tallied until the first 15-min interval. In any case, $M$. rubra arrived $>10$ min before the next fastest species (M. fracticornis mean \pm $\mathrm{SE}=31.6 \pm 4.6 \mathrm{~min}$.) and $>21 \mathrm{~min}$ before all native Myrmica species combined (mean $\pm \mathrm{SE}=42.4 \pm 7.5$ min.).

Temporal Foraging Patterns. Over a 24-h survey period in August 2004, we collected a total of 19 ant 

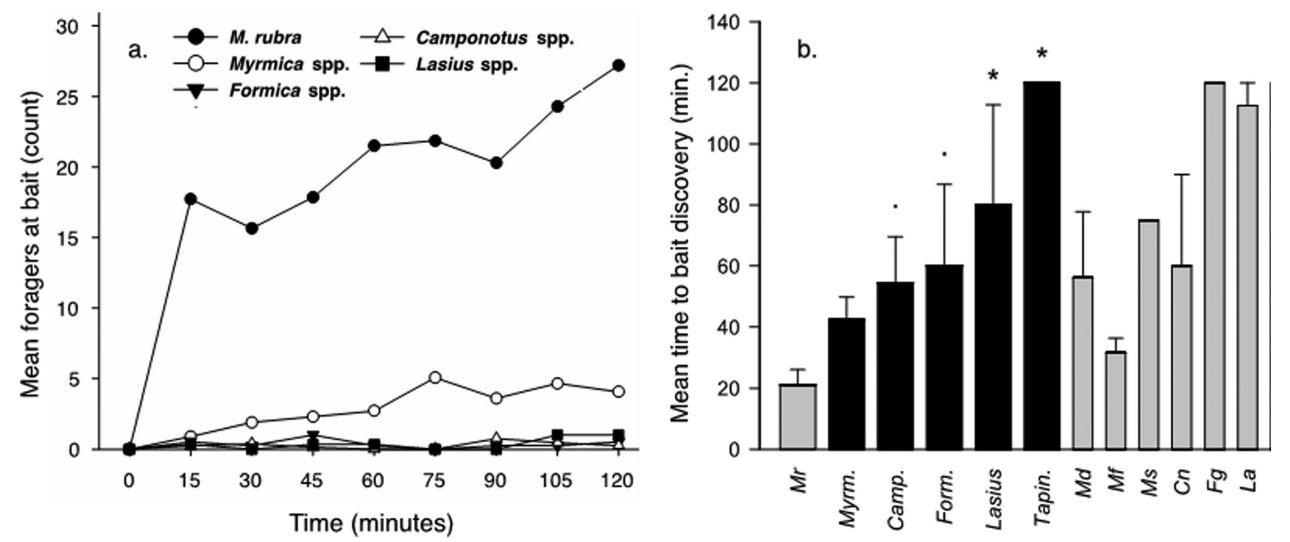

Fig. 4. Mean forager recruitment (a) and time to discovery (b) at sugar baits at a site recently invaded by M. rubra. All ants were identified by sight to genus (black bars); foragers present at the end of the experiment collected and identified to species (gray bars). Symbols above bars correspond to statistical differences with $M$. rubra as follows: “*”: $0.01 \leq P<0.05$; “.": $0.05 \leq P<0.10)$. Foragers at baits were censused at 15-min intervals for $2 \mathrm{~h}$ on the morning of 20 August 2004 . Mr, M. rubra; Myrm., Myrmica spp. (native); Camp., Camponotus spp.; Form., Formica spp.; Md, Myrmica detritinodis; Mf, M. fracticornis; Ms, M. sculptilis (Francouer); Cn, Camponotus novaboracensis; Tapin., Tapinoma sessile (Say); Fg, Formica glacialis; La, Lasius alienus.

species in two invaded and two noninvaded sites. In the highly infested site, only $M$. rubra foragers were encountered at baits, the most likely explanation being prior displacement by this ant. Here, M. rubra foragers were present in high numbers (mean $\pm \mathrm{SD}=22.0 \pm$ 8.7 ) and in nearly every trap, declining moderately in the late evening and early morning hours (Fig. 5 top). Native ant abundance at a moderately infested site and the two noninfested sites showed that on the whole, the native ant fauna likewise foraged around the clock but were only rarely encountered in $>20-30 \%$ of traps (Fig. 5 bottom). M. fracticornis was the most commonly collected native species overall. Forager abundance did not differ between M. rubra and $M$. fracticornis in traps where each was collected (Welsh's $t=0.4$; df $=134.0 ; P=0.68$ ), but the frequency of capture was significantly higher for $M$. rubra (Welsh's $t=7.0 ; \mathrm{df}=1002.0 ; P<0.0001$ ).

\section{Discussion}

Despite the widespread ecological and economic importance of invasive ants globally and the associated decline in richness and abundance within native ant communities, the proximate mechanisms driving competitive displacement have been studied in only a few invading species. Interspecific aggression and competition for food resources represent two often related mechanisms that could lead to competitive exclusion, especially given the generally broad diet overlap among omnivorous temperate ants (Gotelli and Ellison 2002). The predilection of foraging workers of many species for aggressive behavior upon encountering noncolony individuals at enduring resources could lead to attrition and reduce foraging efficiency. This study reveals that direct aggression by M. rubra at food resources and superior performance as both exploitation and interference competitors have the potential to displace native ant foragers, lending support to the possible generality of this mechanism as a proximate cause of native ant displacement by invasive ant species (Human and Gordon 1996, Holway 1999).

The existence of a clear dominance-discovery trade-off in native communities as a general mechanism promoting species coexistence in native, coevolved ant communities has been questioned in recent years (Parr and Gibb 2012). Still, M. rubra foragers are both the first to discover food resources during baiting trials under otherwise natural conditions and to dominate and displace native ants from these food rewards. Our data do not address the question of whether this is a cause or a consequence of invasive success, and it is likely that feedbacks between numerical and behavioral dominance and invasiveness do occur. However, from the perspective of native foragers in Maine, M. rubra is clearly an outlier in terms of competitive dominance hierarchies along at least two critical aspects (dominance and discovery).

Competition in the Native and Invasive Range. One question that arises is whether species that become invasive are preselected for traits that confer dominance in the invasive range. In other words, are invaders dominant where they are native? Studies of M. rubra have shown that interspecific competition is an important factor in shaping associated ant communities in its native Europe. For example, Elmes (1974) showed significant overdispersion and colony segregation between M. rubra and Lasius flavus (F.) in an intensively studied grassland. Direct aggression also occurred between Myrmica species (including M. rubra) and L. flavus in pairwise laboratory competition assays (Moxon 1980). Under natural conditions, native European Myrmica partition habitats along predictable environmental gradient. In Europe, M. rubra 


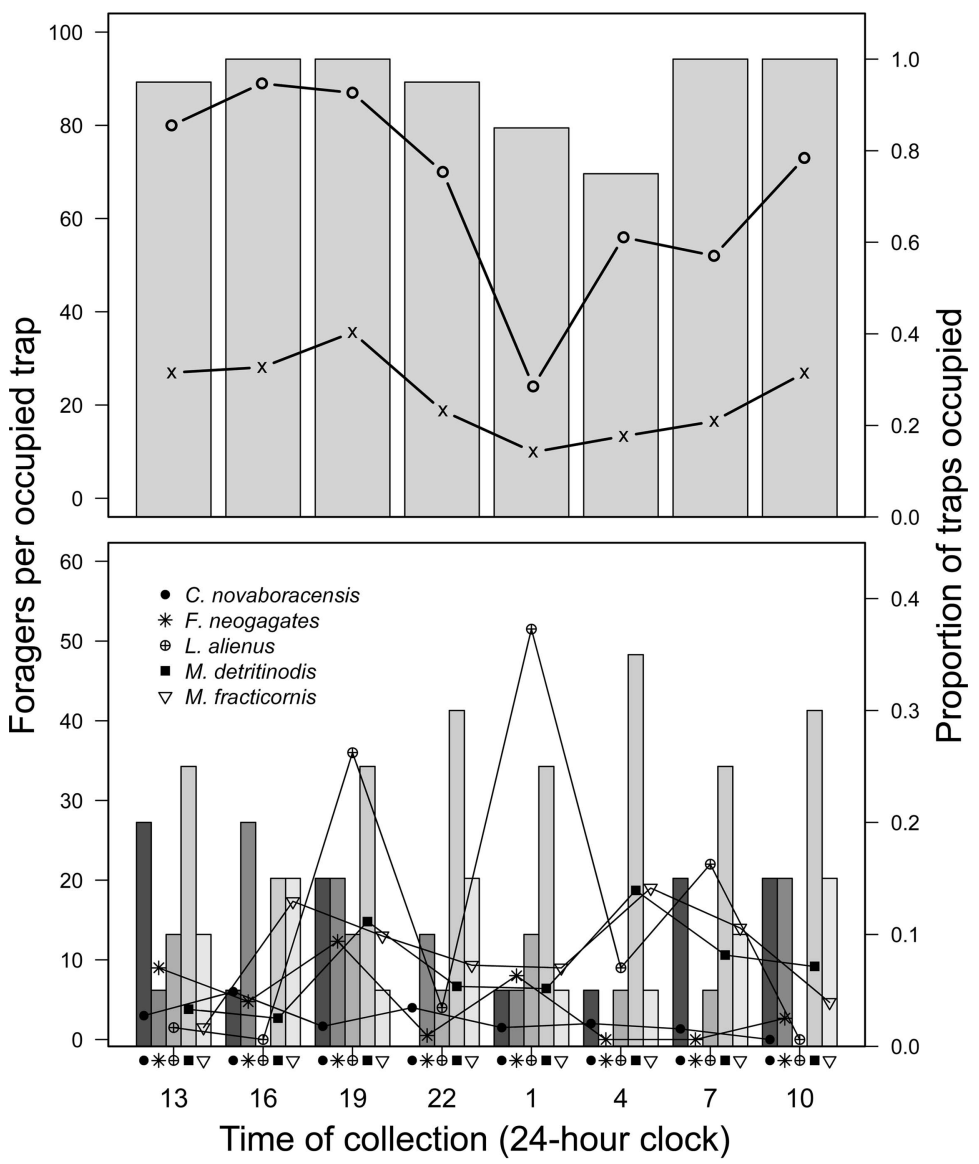

Fig. 5. Temporal foraging patterns in two (of four) sites sampled for $24 \mathrm{~h}$ in August 2004 using sugar-baited vials. In the highly infested site (top), only M. rubra foragers were collected (x: mean foragers per trap; o: maximum per trap). In the uninfested site (bottom), the top five species (by recruitment frequency) are shown. In both subfigures, bars depict the proportion of traps occupied; bar shading in the bottom subfigure corresponds to each of the five most abundant native species collected, as aligned with corresponding symbol.

tends to dominate patches in relatively cool, moist areas but may persist only at low densities under hot or dry conditions (Clarke et al. 1998). In contrast, large, polydomous colonies of Formica (particularly $F$. rufa (L.), F. exsecta (Nylander), and F. truncorum (F.) ) that dominate large areas in the northern boreal forest of Scandinavia have been shown to significantly reduce foraging among Myrmica species (Vepsäläinen and Savolainen 1990). Under certain conditions, however, M. rubra and M. scabrinodis (Nylander) can reach high densities, competitive dominance, and local patch saturation (van der Hammen et al. 2002). As an invasive in eastern North America, M. rubra is dominant across many natural and human-modified habitats. Clearly, M. rubra in North America excels at both exploitative competition (via superior recruitment and rapid discovery of food resources) and interference competition (i.e., direct aggression and dominance from food resources). This suggests that it can and likely does displace native ants under only moderately human-modified landscapes, though the degree to which invasive ants are the "drivers" versus the "passengers" of ecological change is difficult to discern (King and Tschinkel 2006).

Interference Versus Exploitation Competition in North America. Few studies have been performed to date on interspecific competition in ant communities similar to those invaded by M. rubra in the Northeast. Fellers (1987) found evidence of extensive niche partitioning among woodland ants in Maryland, where species of the subfamily Formicinae (Lasius alienus, Prenolepis imparis (Emery), and Formica subsericea(Say)) were shown to be dominant contest competitors. Myrmicines (Aphaenogaster rudis (Enzmann), Myrmica punctiventris (Roger), Myrmica emeryana (Cole), and Temnothorax curvispinosis (Mayr)) were generally submissive upon encountering foragers of a rival species. Like the native Myrmica in Fellers' (1987) work, M. rubra in our study was shown to encounter food resources in advance of sympatric species in our baiting experiments. Indigenous Myrmica species have been ranked as intermediate to subordinate interference competitors in the United States (Fellers 1987) and Europe (Savolainen and 
Vepsäläinen 1988, Vepsäläinen and Savolainen 1990). In contrast, in its invasive range M. rubra was shown to be highly effective at displacing foragers of a variety of native species from baits via direct aggression and contest competition across several experimental conditions, including both captive colony and natural field recruitment assays. Interestingly, displacement was much more rapid and complete at baits relative to aphid colonies, likely due to the structural complexity of a shrub- versus ground-level vegetation. As with the invasive L. humile, M. rubra appears to have broken the trade-off between interference and exploitation competitive ability (Human and Gordon 1996, Holway 1999). Although field trials have confirmed that $M$. rubra competes directly with native foragers at food resources along the boundaries of local infestations, it is not known how much direct or indirect competition for food contributes to the displacement of native ants at a local or regional scale.

Native Ant Defenses. In isolation, localized interactions as observed during aggression assays and within zones of overlap surrounding invaded habitat provide little insight into the long-term impacts of $M$. rubra on the native community. It is likely that given the invader's sheer numerical dominance, it will ultimately displace all but a few native ant species (Holway and Case 2001). Pitfall and litter sampling in invaded and noninvaded territories revealed the persistence of workers of only two relatively cryptic species, Stenamma diecki (Emery) and Lasius subumbratus (Viereck), within areas of infestation compared with 18 species from noninfested areas (this study; J.R.G, unpublished data). These results mirror those of other studies (Porter and Savignano 1990, Cole et al. 1992, Human and Gordon 1999), though there is some evidence that the native community may recover over time (Morrison 2002). Alternatively, ants of the genus Temnothorax may be in a position to potentially withstand the invasion. Owing at least in part to their small size $(2-3 \mathrm{~mm})$, these ants appear to have taken the role of "insinuators" (sensu Wilson 1971), capable of feeding unmolested in the presence of M. rubra and other ants. Temnothorax andrei (Emery) was found to persist in areas overrun by L. humile in California where other species have been displaced (Human and Gordon 1997). Almost no overt aggression was directed toward Temnothorax foragers by $M$. rubra during paired aggression assays, perhaps as a consequence of the former's tiny size. Indeed these ants are the most abundant (and often the only) natives readily found within the boundaries of a dense infestation (personal observation). At the other extreme, Lasius pallitarsis, one of the most abundant ants on Mount Desert Island with habitat requirements broadly overlapping those of M. rubra, was actively predated upon during aggression trials. This may translate to high vulnerability to the M. rubra invasion, supported indirectly by the species' near absence from heavily infested sites (unpublished data). The number of hypogaeic or otherwise cryptic species that are able to persist within an M. rubra infestation is unknown, though such species may be able to avoid contact with M. rubra by foraging underground and beneath the litter, effectively minimizing direct interaction, and may also specialize on distinct food resources, as has been shown in other invaded communities (Ward 1987).

Qualitative Interactions. Despite clear dominance in the majority of aggression assays against native ant species, M. rubra was not always the obvious victor, and the qualitative nature of worker interactions was idiosyncratic by species. Extrapolation from our behavioral assays to patterns of persistence in the longterm is difficult. Whether resilience to M. rubra aggression in the short term or apparent immunity to attack (by virtue of being completely ignored, as with all three species of Temnothorax) corresponds to potential coexistence is unknown. However, it bears mentioning that several species stood out during the aggression assays as better able to defend against $M$. rubra attack. Displacement of native ants was strongly linked to recruitment rate, which was often but not always stronger in M. rubra in the arena assays. However, $D$. taschenbergi consistently recruited to baits in numbers comparable to $M$. rubra, and also employed chemical defenses during aggression assays that caused convulsions, disorientation and sometimes death in M. rubra foragers. Similarly, C. cerasi was observed to possess a potent venom; despite the small size of its workers numerous M. rubra workers were killed during the aggression trials. Like D. taschenbergi, C. cerasi was also able to ward off a short-term M. rubra attack in defense of their aphid resource, though this could be due to the structural complexity of the branch substrate.

Alternative Modes of Displacement. A number of other mechanisms could contribute to the displacement of native ant species from an invaded habitat beyond direct or indirect competition for food resources. Competition for territory or nest sites, colony raiding or predation on reproductive propagules or incipient colonies may be part of the story pertaining to the current dominance by M. rubra. However, nest sites do not appear to be limiting (given a $\approx 50 \%$ vacancy rate among artificial substrates placed and monitored in infested and uninfested sites during 2002-2004; unpublished data). In the long-term, complex feedbacks linked to changes in community structure and ecosystem services (e.g., seed dispersal), acquired or introduced natural enemies, and the potential application of management and control measures could drive ultimate outcomes (Holway 1999).

Population Structure and Competitive Dominance. Numerical dominance may be key to the ecological success of ant species (Davidson 1998; Holway 1998, 1999; Palmer 2004). This may be especially true in invasive ants where mechanisms promoting intraspecific territoriality (e.g., reduced genetic and cuticular chemical signature) may be absent, or if invaders experience lower costs as a result of living in highdensity populations (Giraud et al. 2002). For example, natural enemies such as phorid fly parasitoids have also been shown to directly dampen foraging behavior in Solenopsis invicta (Buren, 1972), with effects on competitive dominance hierarchies (Orr et al. 1995). 
While M. rubra has been shown not to be truly unicolonial in that aggression among neighboring colonies does occur (increasing with distance within and among sites; Garnas et al. 2007), colonies are able to coexist at extremely high densities, with likely effects on competitive hierarchies. Our studies clearly demonstrate that invasive populations of M. rubra outcompete native ants in the acquisition of food, implicating the ant's dominance in both interference and exploitation competition as key to native ant exclusion from food resources.

\section{Acknowledgments}

We thank for their assistance Dave Manski, Judy HazenConnery, Graham Elmes, André Francouer, and numerous student assistants from the University of Maine and Bates College. This research was supported by a grant from the U.S. National Parks Service at Acadia National Park and the Maine Agricultural and Forestry Experiment Station. This is MAFES Publication No. 3384.

\section{References Cited}

Achury, R., P. C. Ulloa, and A. M. Arcila. 2008. Ant composition and competitive interactions with Wasmannia auropunctata in Tropical Dry Forest fragments. Rev. Colomb. Entomol. 34: 209-216.

Adler, F. R., E. G. LeBrun, and J.D.H. Feener. 2007. Maintaining diversity in an ant community: modeling, extending, and testing the dominance-discovery trade-off. Am. Nat. 169: 323-333.

Andersen, A. 2008. Not enough niches: non-equilibrial processes promoting species coexistence in diverse ant communities. Austral Ecol. 33: 211-220.

Carpintero, S., and J. Reyes-Lopez. 2008. The role of competitive dominance in the invasive ability of the Argentine ant (Linepithema humile). Biol. Invasions 10: 25-35.

Clarke, R. T., J. A. Thomas, G. W. Elmes, J. C. Wardlaw, M. L. Muguira, and M. E. Hochberg. 1998. Population modeling of the spatial interactions between Maculinea rebeli, their initial foodplant Gentiana cruciata and Myrmica ants. J. Insect Conserv. 2: 29-37.

Cole, F. R., A. C. Medeiros, L. L. Loope, and W. W. Zuehlke. 1992. Effects of the Argentine ant on arthropod fauna of Hawaiian high-elevation shrubland. Ecology 73: 13131322.

Collingwood, C. A. 1979. The Formicidae (Hymenoptera) of Fennoscandia and Denmark. Fauna Entomol. Scand. 8: $1-174$.

Davidson, D. W. 1998. Resource discovery versus resource domination in ants: a functional mechanism for breaking the trade-off. Ecol. Entomol. 23: 484-490.

de Vroey, C. 1980. Mesure de l'agressivite chez Myrmica rubra (M. laevinodis, Formicidae). Biol. Behav. 5: 37-46.

Elmes, G. W. 1974. The spatial distribution of a population of two ant species living in limestone grassland. Pedobiologia 14: 412-418.

Fellers, J. H. 1987. Interference and exploitation in a guild of woodland ants. Ecology 68: 1466-1478.

Garnas, J. R., F. A. Drummond, and E. Groden. 2007. Intercolony aggression within and among local populations of the invasive ant, Myrmica rubra (Hymenoptera: Formicidae), in coastal Maine. Environ Entomol. 36: 105-113.
Gause, G. F. 1932. Experimental studies on the struggle for existence I. Mixed population of two species of yeast. J. Exp. Biol. 9: 389-402.

Giraud, T., J. S. Pedersen, and L. Keller. 2002. Evolution of supercolonies: the Argentine ants of southern Europe. Proc. Natl. Acad. Sci. USA 99: 6075-6079.

Gotelli, N. J., and A. M. Ellison. 2002. Assembly rules for New England ant assemblages. Oikos 99: 591-599.

Groden, E., F. A. Drummond, J. Garnas, and A. Franceour. 2005. Distribution of an invasive ant, Myrmica rubra (Hymenoptera: Formicidae), in Maine. J. Econ. Entomol. 98: 1774-1784.

Heller, N. E., N. J. Sanders, J. W. Shors, and D. M. Gordon. 2008. Rainfall facilitates the spread, and time alters the impact, of the invasive Argentine ant. Oecologia 155: 385-395.

Helms, K. R., and S. B. Vinson. 2008. Plant resources and colony growth in an invasive ant: the importance of honeydew-producing Hemiptera in carbohydrate transfer across trophic levels. Environ. Entomol. 37: 487-493.

Hölldobler, B., and E. O. Wilson. 1990. The ants. Harvard University Press, Cambridge, MA.

Holm, S. 1979. A simple sequentially rejective multiple test procedure. Scand. J. Stat. 6: 65-70.

Holway, D. 1998. Effect of Argentine ant invasions on ground-dwelling arthropods in northern California riparian woodlands. Oecologia 116: 252-258.

Holway, D. 1999. Competitive mechanisms underlying the displacement of native ants by the invasive Argentine ant. Ecology 80: 238-251.

Holway, D. A., and T. J. Case. 2001. Effects of colony-level variation on competitive ability in the invasive Argentine ant. Anim. Behav. 61: 1181-1192.

Holway, D. A., and A. V. Suarez. 2006. Homogenization of ant communities in mediterranean California: the effects of urbanization and invasion. Biol. Conserv. 127: 319-326.

Holway, D. A., L. Lach, A. V. Suarez, N. D. Tsutsui, and T. J. Case. 2002. The causes and consequences of ant invasions. Ann. Rev. Ecol. Syst. 33: 181-233.

Human, K., and D. Gordon. 1996. Exploitation and interference competition between the invasive Argentine ant Linepithema humile, and native ant species. Oecologia 105: 405-412.

Human, K., and D. Gordon. 1997. Effects of Argentine ants on invertebrate biodiversity in northern California. Conserv. Biol. 11: 1242-1248.

Human, K., and D. Gordon. 1999. Behavioral interactions of the invasive Argentine ant with native ant species. Insectes Soc. 46: 159-163.

Kenis, M., M. A. Auger-Rozenberg, A. Roques, L. Timms, C. Pere, M. Cock, J. Settele, S. Augustin, and C. LopezVaamonde. 2009. Ecological effects of invasive alien insects. Biol. Invasions 11: 21-45.

King, J. R., and W. R. Tschinkel. 2006. Experimental evidence that the introduced fire ant, Solenopsis invicta, does not competitively suppress co-occurring ants in a disturbed habitat. J. Anim. Ecol. 75: 1370-1378.

Kronfeld-Schor, N. 2003. Partitioning of time as an ecological resource. Ann Rev. Ecol Syst. 34: 153-181.

Lessard, J. P., R. R. Dunn, and N. J. Sanders. 2009a. Temperature-mediated coexistence in temperate forest ant communities. Insectes Soc. 56: 149-156.

Lessard, J. P., J. A. Fordyce, N. J. Gotelli, and N. J. Sanders. 2009b. Invasive ants alter the phylogenetic structure of ant communities. Ecology 90: 2664-2669.

McPhee, K., J. R. Garnas, F. Drummond, and E. Groden. 2012. Homopterans and an Invasive red ant, Myrmica rubra (L.), in Maine. Environ. Entomol. 41: 59-71. 
Menke, S. B., and D. A. Holway. 2006. Abiotic factors control invasion by Argentine ants at the community scale. J. Anim. Ecol. 75: 368-376.

Morrison, L. 2002. Long-term impacts of an arthropodcommunity invasion by the imported fire ant, Solenopsis invicta. Ecology 83: 2337-2345.

Moxon, J. E. 1980. Comparative analysis of the interspecific aggressive behaviour of some British ants, with particular reference to Myrmica spp. and Lasius flavus L. Ph.D. dissertation, University of London, London, England.

Orr, M. R., S. H. Seiki, W. W. Benson, and L. E. Gilbert. 1995. Flies suppress fire ants. Nature 373: 292.

Ouellette, G., F. Drummond, B. Choate, and E. Groden. 2010. Ant diversity and distribution in Acadia National Park, Maine. Environ. Entomol. 39: 1447-1556.

Palmer, T. 2003. Spatial habitat heterogeneity influences competition and coexistence in an African acacia ant guild. Ecology 84: 2843-2855.

Palmer, T. M. 2004. Wars of attrition: colony size determines competitive outcomes in a guild of African acacia ants. Anim. Behav. 68: 993-1004.

Parr, C., and H. Gibb. 2012. The discovery-dominance trade-off is the exception, rather than the rule. J. Anim. Ecol. 81: 233-241.

Passera, L., and D. F. Williams. 1994. Characteristics of tramp species, pp. 23-43. In D. F. Williams (ed.), Exotic ants: biology, impact, and control of introduced species. Westview Press, Boulder, CO.

Pearce-Duvet, J.M.C., M. Moyano, F. R. Adler, and D. H. Feener. 2011. Fast food in ant communities: how competing species find resources. Oecologia 167: 229-240.

Porter, S. D., and D. A. Savignano. 1990. Invasion of polygyne fire ants decimates native ants and disrupts arthropod community. Ecology 71: 2095-2106.

Porter, S. D., D. F. Williams, R. S. Patterson, and H. Fowler. 1997. Intercontinental differences in the abundance of Solenopsis Fire ants (Hymenoptera: Formicidae): Escape from natural enemies. Environ. Entomol. 26: 373-384.

R Core Team. 2012. R: a language and environment for statistical computing. R Core Team, Vienna, Austria.

Radchenko, A., and G. W. Elmes. 2010. Myrmica ants (Hymenoptera: Formicidae) of the Old World, vol. 3. Fundacja Natura Optima Dux, Warsaw, Poland.

Rowles, A. D., and D. J. O'Dowd. 2009. Impacts of the invasive Argentine ant on native ants and other invertebrates in coastal scrub in southeastern Australia. Austral Ecol. 34: 239-248.

Ryti, R. T., and T. J. Case. 1984. Spatial arrangement and diet overlap between colonies of desert ants. Oecologia 62: 401-404

Sanders, N. J., K. E. Barton, and D. M. Gordon. 2001. Longterm dynamics of the distribution of the invasive Argentine ant, Linepithema humile, and native ant taxa in Northern California. Oecologia 127: 123-130.
Sanders, N. J., N. J. Gotelli, N. E. Heller, and D. M. Gordon. 2003. Community disassembly by an invasive species. Proc. Natl. Acad. Sci. USA 100: 2474-2477.

Savolainen, R., and K. Vepsäläinen. 1988. A competition hierarchy among boreal ants: impact on resource partitioning and community structure. Oikos 51: 135-155.

Shik, J. Z., and J. Silverman. 2012. Towards a nutritional ecology of invasive establishment: aphid mutualists provide better fuel for incipient Argentine ant colonies than insect prey. Biol. Invasions 15: 829-836.

Starks, P. 2003. Selection for uniformity: xenophobia and invasion success. Trends Ecol. Evol.ution. 18: 159-162.

Systat Software, I. 2012. SYSTAT for windows: statistics, version 11.00.01. Systat Software, Richmond, CA.

Tokeshi, M. 1999. Species coexistence., Wiley-Blackwell, London, United Kingdom.

Tsutsui, N. D., A. V. Suarez, D. A. Holway, and T. J. Case. 2000. Reduced genetic variation and the success of an invasive species. Proc. Natl. Acad. Sci. USA 97: 5948-5953.

Tsutsui, N. D., S. N. Kauppinen, A. F. Oyafuso, and R. K. Grosberg. 2003. The distribution and evolutionary history of Wolbachia infection in native and introduced populations of the invasive Argentine ant (Linepithema humile). Mol. Ecol. 12: 3057-3068.

van der Hammen, T., J. Pedersen, and J. Boomsma. 2002. Convergent development of low-relatedness supercolonies in Myrmica ants. Heredity 89: 83-89.

Vepsäläinen, K., and R. Savolainen. 1990. The effects of interference by Formicine ants on the foraging of Myrmica. J. Anim. Ecol. 59: 643-654.

Ward, P. 1987. Distribution of the introduced Argentine ant (Iridomyrmex humilis) in natural habitats of the Lower Sacramento Valley and its effects on the indigenous ant fauna. Hilgardia 55: 1-16.

Wetterer, J. K., and A. G. Radchenko. 2011. Worldwide spread of the ruby ant, Myrmica rubra (Hymenoptera: Formicidae). Myrmecol. News 14: 87-96.

Wheeler, W. M. 1908. A European ant (Myrmica laevinodis) introduced into Massachusetts. J. Econ. Entomol. 1: $336-339$

Wilder, S. M., D. A. Holway, A. V. Suarez, E. G. LeBrun, and M. D. Eubanks. 2011. Intercontinental differences in resource use reveal the importance of mutualisms in fire ant invasions. Proc. Natl. Acad. Sci. USA 108: 20639-20644.

Wilson, E. O. 1971. The insect societies. Bellknap Press, Cambridge, MA.

Yang, C.-C., Y.-C. Yu, S. M. Valles, D. H. Oi, Y.-C. Chen, D. Shoemaker, W.-J. Wu, and C.-J. Shih. 2010. Loss of microbial (pathogen) infections associated with recent invasions of the red imported fire ant Solenopsis invicta. Biol. Invasions 12: 3307-3318.

Received 24 March 2014; accepted 29 August 2014. 